Supporting Information:

\title{
3D Atomic Understanding of Functionalized Carbon Nanostructures for Energy Applications
}

\author{
Carbon Sphere Synthesis and Characterization - S-2 \\ N 1s Peak Assignment Rationale and Fitting Parameters - S-4 \\ FIB Preparation Considerations - S-6 \\ Cross Correlation TEM Images of APT tips - S-7 \\ Atom Probe Reconstruction Parameters and Mass Spectra - S-8
}

Chilan Ngo, ${ }^{1 \&}$ Margaret Fitzgerald, ${ }^{1 \&}$ Michael J. Dzara, ${ }^{1}$ Matthew B Strand, ${ }^{1}$ David R. Diercks, ${ }^{2}$ Svitlana Pylypenko ${ }^{{ }^{*}}$

${ }^{1}$ Department of Chemistry, Colorado School of Mines, Golden, CO, 80401

${ }^{2}$ Department of Metallurgical and Materials Engineering, Colorado School of Mines, Golden, CO, 80401

*Corresponding Author Email: spylypen@mines.edu

\&These authors contributed equally to this work. 


\section{Carbon Sphere Synthesis and Characterization}
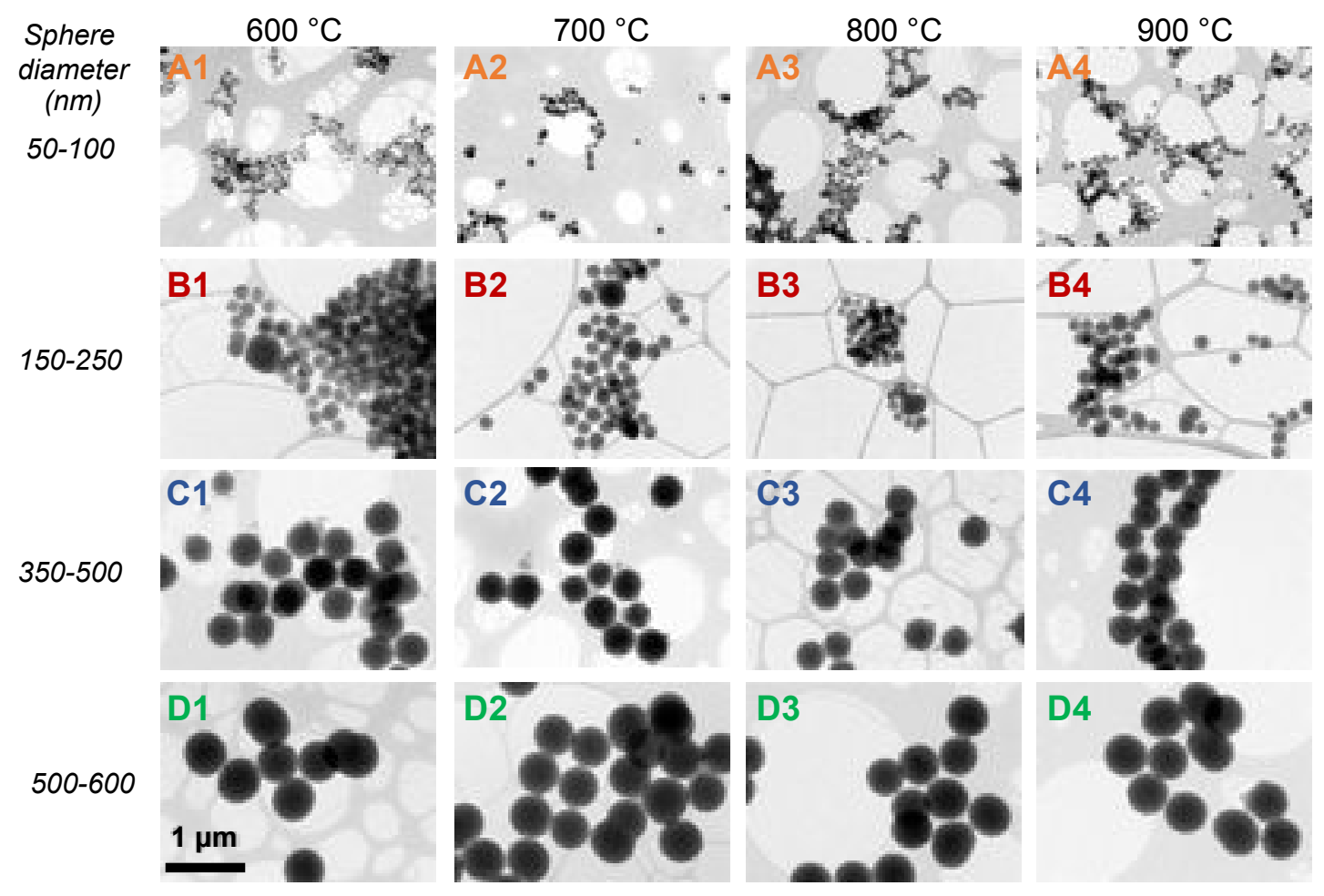

Figure S1: Bright field TEM images of N-Cs after pyrolyzation in N2. Decreasing amounts of EDA used for this synthesis presented as: (A) 01.31 vol. \%, (B) 1.18 vol. \%, (C) 1.05 vol. \%, and (D) 0.7 vol. \% yield. These decreasing volumes produced nanospheres of steadily increasing diameter. Pyrolyzation temperatures of (1) $600{ }^{\circ} \mathrm{C}$, (2) $700{ }^{\circ} \mathrm{C}$, (3) $800{ }^{\circ} \mathrm{C}$, and (4) $900{ }^{\circ} \mathrm{C}$ do not significantly impact diameter. All images were taken under the same operating conditions. 
Table S1: Particle sphere size ranges (nm) obtained by TEM images demonstrating the size control by varying volume percent of EDA.

\begin{tabular}{cc|cccc} 
Sample notation & $\begin{array}{c}\text { vol. \% } \\
\text { EDA }\end{array}$ & $600{ }^{\circ} \mathrm{C}$ & $700{ }^{\circ} \mathrm{C}$ & $800{ }^{\circ} \mathrm{C}$ & $900{ }^{\circ} \mathrm{C}$ \\
\hline A & 1.31 & $50-100$ & $50-100$ & $50-100$ & $50-100$ \\
B & 1.18 & $150-250$ & $150-250$ & $150-250$ & $150-250$ \\
C & 1.05 & $350-500$ & $350-500$ & $350-500$ & $350-500$ \\
D & 0.7 & $500-600$ & $500-600$ & $500-600$ & $500-600$
\end{tabular}

Table S2: Elemental composition as determined by STEM/EDS and XPS are compared at $700{ }^{\circ} \mathrm{C}$ and $800{ }^{\circ} \mathrm{C}$. XPS percentages determined from $\mathrm{C} 1 \mathrm{~s}, \mathrm{O} 1 \mathrm{~s}$, and $\mathrm{N} 1 \mathrm{~s}$ spectra of $\mathrm{N}-\mathrm{C}_{\mathrm{sph}}$

\begin{tabular}{c|cccc} 
& \multicolumn{4}{|c}{ Pyrolyzation Temperature } \\
\hline at. \% & \multicolumn{3}{|c}{$\mathbf{7 0 0}^{\circ} \mathbf{C}$} & \multicolumn{3}{c}{$\mathbf{8 0 0}^{\circ} \mathbf{C}$} \\
Element & STEM/EDS & XPS & STEM/EDS & XPS \\
\hline $\mathrm{C}$ & 95.5 & 94.6 & 91.3 & 94.3 \\
$\mathrm{~N}$ & 3 & 2.4 & 5.76 & 3.2 \\
$\mathrm{O}$ & 1.5 & 3 & 2.9 & 2.5
\end{tabular}




\section{N 1s Fitting - Peak Assignment Rationale}

The peak at lowest BE $(397.2$ - $397.5 \mathrm{eV})$ can be assigned to a variety of electron-rich nitrogen species (denoted as N-rich) such as carbon-nitride, triazine and other azines, and nitrogen clusters in pores. Peaks at 397.9 - 398.1 eV and 398.6 - 398.8 eV are typically attributed to electron-rich nitrogen species with a lone pair, namely imines at lower BE and pyridine at slightly higher BE. The component at 399.3 - $399.5 \mathrm{eV}$ can be ascribed to either amine or nitrile species. Hydrogenated nitrogen species such as pyrrole and H-pyridine are typically found in the range of $400-401 \mathrm{eV}$, where we do observe two peaks located at 399.9-400.1 and 400.6-400.8 eV, with the H-pyridine component at this BE corresponding to an in-plane conformation. The next two higher BE peaks are assigned to graphitic nitrogen species, with the lower of the two peaks (401.2 $-401.4 \mathrm{eV}$ ) corresponding to graphitic $\mathrm{N}$ in a disordered environment (i.e. in close proximity to other defects) while the higher BE (402.0 - 402.2 eV) graphitic nitrogen corresponds to a more well-ordered environment, more along the lines of a nitrogen point defect in a graphitic structure. The final component $402.8-403.1 \mathrm{eV}$ can be assigned to H-pyridine in an edge conformation, or oxidized organic nitrogen species.
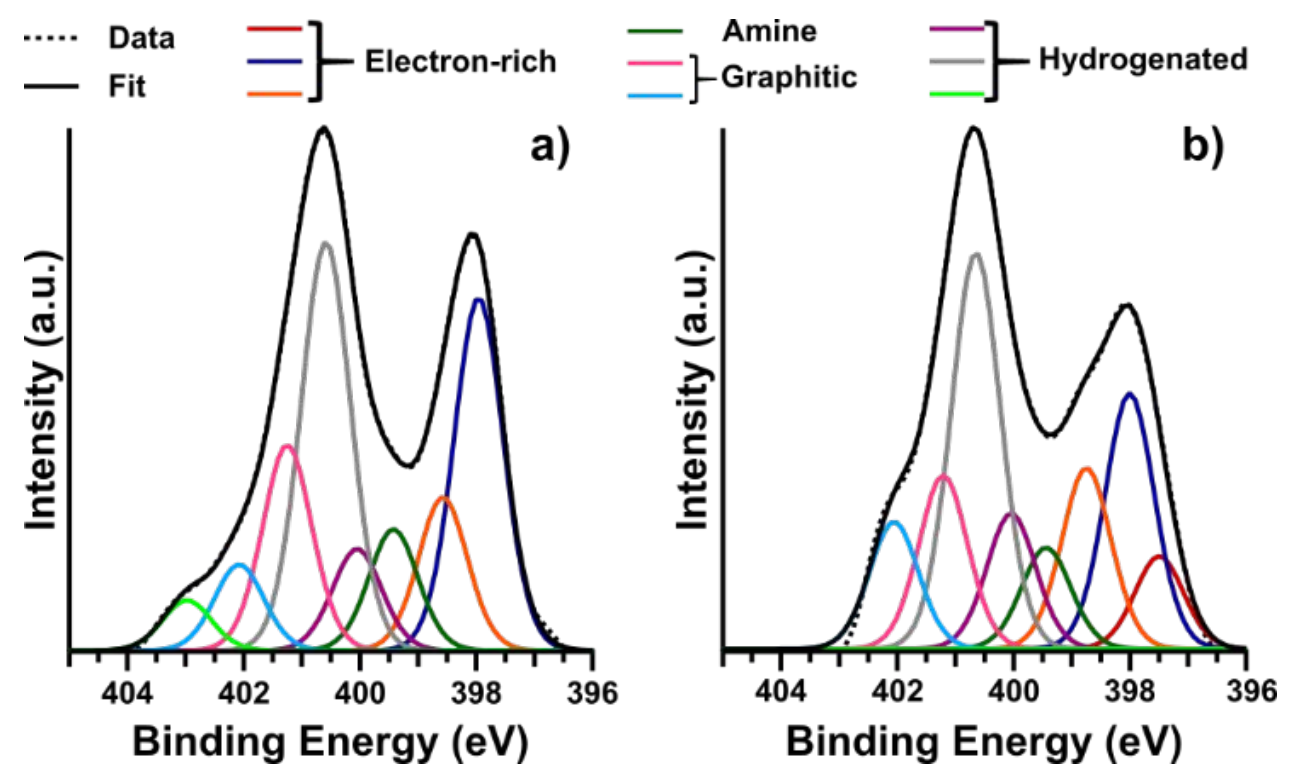

Figure S2: The relative abundance of nitrogen species in N-Cs is evaluated by curve-fitting, applied to N-Cs pyrolyzed at $700^{\circ} \mathrm{C}$ (a) and $800{ }^{\circ} \mathrm{C}(\mathrm{b})$. 


\section{N 1s Fitting Parameters:}

Table S3: Fitting parameters (BE and relative percentage of the fit) of the N 1s are displayed. The FWHM of all components is $1.0 \mathrm{eV}$.

\begin{tabular}{|c|c|c|c|c|c|c|c|c|}
\hline \multirow[b]{3}{*}{ N Species } & \multicolumn{8}{|c|}{ Pyrolyzation Temperature } \\
\hline & \multicolumn{2}{|c|}{$600^{\circ} \mathrm{C}$} & \multicolumn{2}{|c|}{$700{ }^{\circ} \mathrm{C}$} & \multicolumn{2}{|c|}{$800{ }^{\circ} \mathrm{C}$} & \multicolumn{2}{|c|}{$900^{\circ} \mathrm{C}$} \\
\hline & $\mathrm{BE}$ & $\%$ Fit & $\mathrm{BE}$ & $\%$ Fit & $\mathrm{BE}$ & $\%$ Fit & $\mathrm{BE}$ & $\%$ Fit \\
\hline \multirow{3}{*}{ Electron-rich } & 397.3 & 3.2 & 397.2 & 0.4 & 397.5 & 6.3 & 397.4 & 0.0 \\
\hline & 398.1 & 25.1 & 398.0 & 23.6 & 398.0 & 17.5 & 397.9 & 12.9 \\
\hline & 398.6 & 17.8 & 398.6 & 10.3 & 398.8 & 12.4 & 398.7 & 8.8 \\
\hline Amine & 399.5 & 4.5 & 399.4 & 8.1 & 399.4 & 7.0 & 399.5 & 1.8 \\
\hline \multirow{2}{*}{$\begin{array}{l}\text { Hydrogenated } \\
\text { (in-plane) }\end{array}$} & 400.1 & 14.7 & 400.1 & 6.9 & 400.0 & 9.2 & 399.9 & 9.5 \\
\hline & 400.7 & 23.1 & 400.6 & 27.6 & 400.7 & 27.2 & 400.7 & 31.4 \\
\hline \multirow{2}{*}{ Graphitic } & 401.2 & 8.3 & 401.3 & 13.9 & 401.2 & 11.8 & 401.4 & 15.4 \\
\hline & 402.2 & 3.2 & 402.1 & 5.8 & 402.1 & 8.6 & 402.1 & 10.8 \\
\hline $\begin{array}{l}\text { Hydrogenated } \\
\text { (edge) }\end{array}$ & 402.9 & 0.2 & 403.0 & 3.4 & 403.0 & 0.0 & 403.1 & 9.3 \\
\hline
\end{tabular}




\section{FIB Preparation Considerations}

Table S4: Summary of FIB conditions for preparation of APT posts on GaAs. Z height / times increase as harder materials are used, and unlisted XY dimensions vary according to individual samples. Note: For all APT samples, Pt deposited by the FIB should not remain on the tip, as it consists of Pt nanoparticles in a $\mathrm{C}$ matrix that provides poor field evaporation ${ }^{1-3}$ However, there often is leftover capping material that cannot be eliminated without affecting the entire $\mathrm{N}-\mathrm{C}$ sample. When impossible to fully remove, the Pt layer should be no more than $20 \mathrm{~nm}$

\begin{tabular}{|c|c|c|c|c|c|c|}
\hline Step & Description & Tilt & Pattern & $\begin{array}{l}\text { Dimensions } \\
\quad(X Y Z)\end{array}$ & $\begin{array}{l}\text { I-beam } \\
\text { current }\end{array}$ & Purpose / Notes \\
\hline \multirow{2}{*}{1} & E-beam Pt & $0^{\circ}$ & Rectangle Pt & $2.5 \times 1.5 \times 0.3 \mu \mathrm{m}$ & -- & $\begin{array}{c}\text { Gently deposit layer of protective } \mathrm{Pt} \\
\text { over targeted area }\end{array}$ \\
\hline & $\begin{array}{l}\text { I-beam Pt } \\
\text { (as-needed) }\end{array}$ & $52^{\circ}$ & Rectangle Pt & $2.5 \times 1.5 \times 0.2 \mu \mathrm{m}$ & $\begin{array}{r}80 \mathrm{pA} \\
(30 \mathrm{kV})\end{array}$ & Quickly deposit thicker layer of Pt \\
\hline \multirow{3}{*}{2} & Trenches & $52^{\circ}$ & $\begin{array}{l}\text { Regular } \\
\text { cross section }\end{array}$ & $7.5 \times 5 \times 9 \mu \mathrm{m}$ & $21 \mathrm{nA}$ & $\begin{array}{l}\text { Mill out sides above and below protected } \\
\text { area }\end{array}$ \\
\hline & U-cut front & $0^{\circ}$ & Rectangles & $\begin{array}{l}1.5 \times 5.5 \times 3 \mu \mathrm{m} \\
7.0 \times 4.5 \times 3 \mu \mathrm{m} ; \\
1.5 \times 3.5 \times 3 \mu \mathrm{m}\end{array}$ & $2.5 \mathrm{nA}$ & $\begin{array}{l}\text { In parallel, detach } 2.5 \text { remaining sides } \\
\text { from rough sample slice }\end{array}$ \\
\hline & U-cut back & $0^{\circ}$ & Rectangles & $\begin{array}{l}1.5 \times 3.5 \times 3 \mu \mathrm{m} \\
7.0 \times 4.5 \times 3 \mu \mathrm{m} ; \\
1.5 \times 5.5 \times 3 \mu \mathrm{m}\end{array}$ & $2.5 \mathrm{nA}$ & $\begin{array}{l}\text { At } 180^{\circ} \text { stage rotation, mill } \\
\text { corresponding areas on backside }\end{array}$ \\
\hline \multirow{2}{*}{3} & $\begin{array}{l}\text { Attach } \\
\text { needle }\end{array}$ & $0^{\circ}$ & Rectangle Pt & $\mathrm{Z}: 1 \mu \mathrm{m} *$ & $80 \mathrm{pA}$ & $\begin{array}{l}\text { Weld dettached sample end to } \\
\text { Omniprobe needle }\end{array}$ \\
\hline & $\begin{array}{l}\text { Detach } \\
\text { sample }\end{array}$ & $0^{\circ}$ & Rectangle & $3.5 \times 1 \times 3 \mu \mathrm{m}$ & $2.5 \mathrm{nA}$ & $\begin{array}{l}\text { Remove sample from bulk by milling } \\
\text { away final attached end }\end{array}$ \\
\hline \multirow{3}{*}{4} & Attach post & $0^{\circ}$ & Rectangle & $\mathrm{Z}: 1 \mu \mathrm{m}$ & $40 \mathrm{pA}$ & Adhere sample to post \\
\hline & $\begin{array}{l}\text { Detach } \\
\text { needle }\end{array}$ & $0^{\circ}$ & $\begin{array}{l}\text { Rectangle, } \\
\text { rotated }\end{array}$ & $3.5 \times 1 \times 3 \mu \mathrm{m}$ & $2.5 \mathrm{nA}$ & Remove needle from sample \\
\hline & $\begin{array}{l}\text { Attach post } \\
\text { backside }\end{array}$ & $0^{\circ}$ & $\begin{array}{l}\text { Rectangle, } \\
\text { rotated }\end{array}$ & $\mathrm{Z}: 1 \mu \mathrm{m}$ & $40 \mathrm{pA}$ & $\begin{array}{c}\text { At } 200^{\circ} \text { stage rotation, weld backside to } \\
\text { post }\end{array}$ \\
\hline 5 & Clean front & $52^{\circ}$ & $\begin{array}{c}\text { Cleaning } \\
\text { cross section }\end{array}$ & $\mathrm{Z}: 0.5-1 \mu \mathrm{m}$ & $80 \mathrm{pA}$ & $\begin{array}{l}\text { Gradually clear front of post until } \\
\text { targeted feature just visible }\end{array}$ \\
\hline \multirow{3}{*}{6} & $\begin{array}{l}\text { Clean sides, } \\
\text { back }\end{array}$ & $52^{\circ}$ & $\begin{array}{l}\text { Cleaning } \\
\text { cross section }\end{array}$ & $\mathrm{Z}: 0.5-1 \mu \mathrm{m}$ & $80 \mathrm{pA}$ & $\begin{array}{l}\text { Clear sides \& back to center targeted } \\
\text { feature in } 250 \sim 150 \mathrm{~nm} \text { width post }\end{array}$ \\
\hline & $\begin{array}{c}\text { Clear } \\
\text { satellites }\end{array}$ & $52^{\circ}$ & $\begin{array}{l}\text { Cleaning } \\
\text { cross section }\end{array}$ & $\mathrm{Z}: 1 \mu \mathrm{m}$ & $80 \mathrm{pA}$ & Clear satellites, as seen in e-beam \\
\hline & $\begin{array}{c}\text { Check } \\
\text { satellites }\end{array}$ & $0^{\circ}$ & $\begin{array}{c}\text { Cleaning } \\
\text { cross section }\end{array}$ & $\mathrm{Z}: 1 \mu \mathrm{m}$ & $80 \mathrm{pA}$ & $\begin{array}{l}\text { Check remaining satellites in i-beam, re- } \\
\text { tilt to clear }\end{array}$ \\
\hline 7 & Final thin & $52^{\circ}$ & Circle & $\sim 50 \mathrm{~nm}$ & $\begin{array}{l}72 \mathrm{pA} \\
(2 \mathrm{kV})\end{array}$ & $\begin{array}{l}\text { Thin to sharpen pillar and remove } \mathrm{Pt}(20 \\
-50 \mathrm{~nm} \text { max remaining, as seen in TEM) }\end{array}$ \\
\hline
\end{tabular}




\section{Cross Correlation TEM Images}

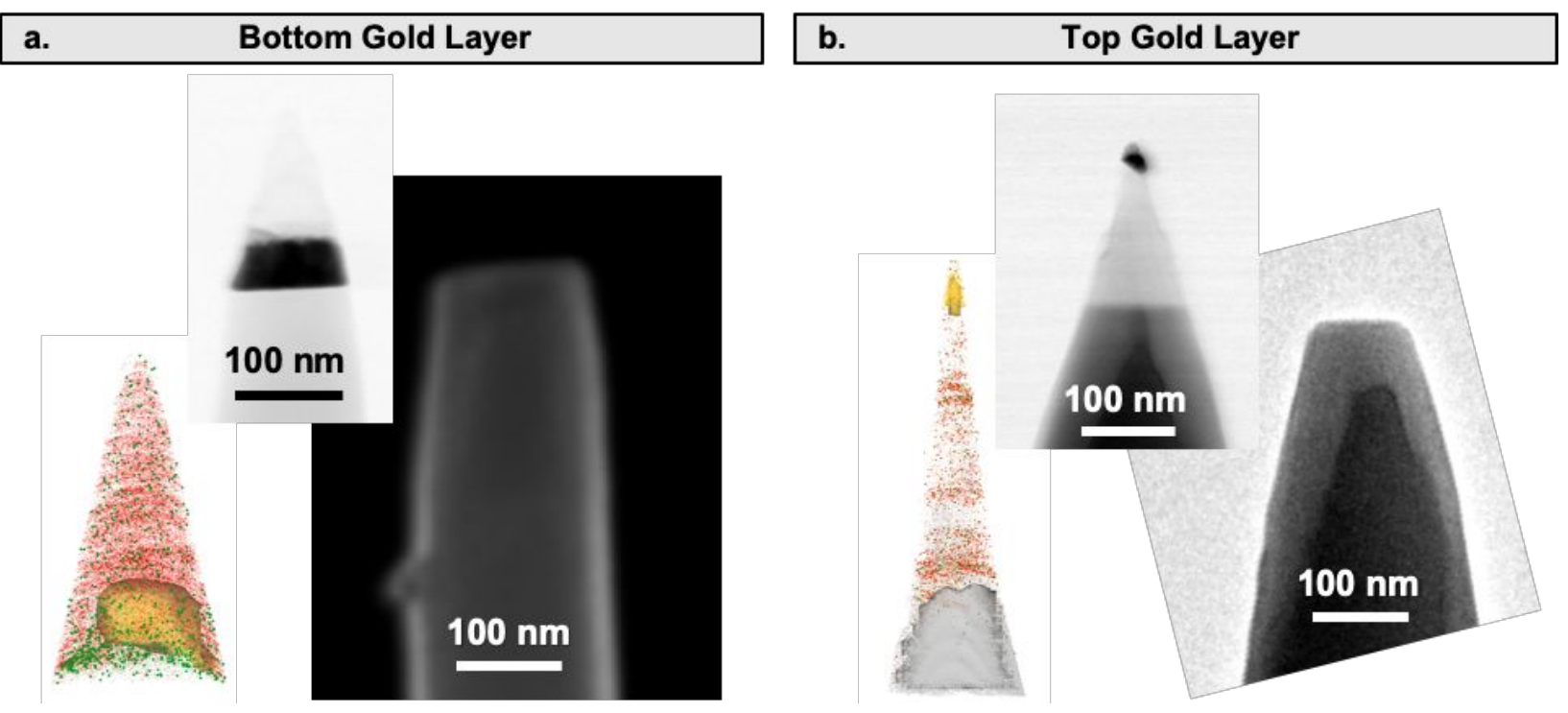

Figure S3: STEM imaging before and after APT, showing that both samples from Figure 6 have been evaporated past the N-Cs and Au layers. These images are used for verification of sphere location and tip shape to enhance the accuracy of the reconstruction. Note that the flat top of the post-run samples suggests delamination of the gold during evaporation. Further optimization of LEAP parameters is needed to prevent delamination in the future. 


\section{Atom Probe Reconstruction Parameters:}

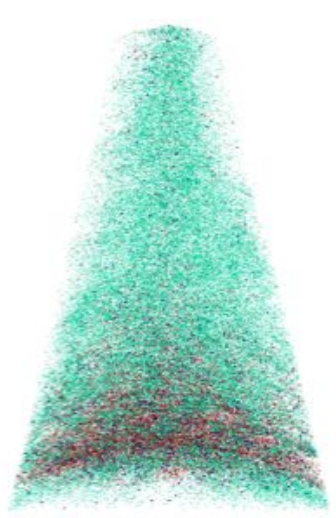

A

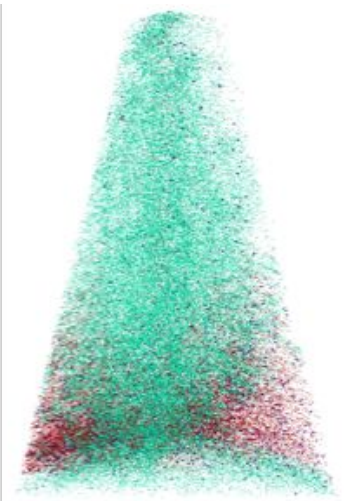

B

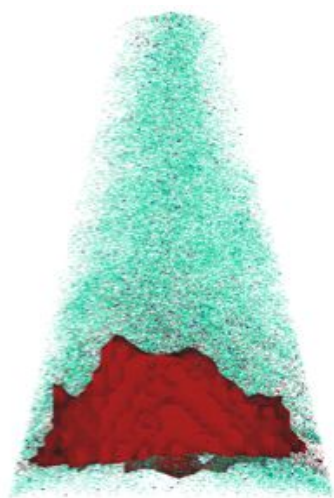

C

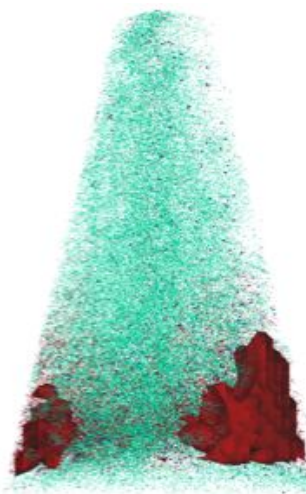

D

20nm

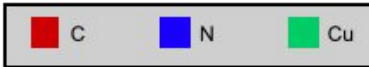

Figure S4: Enlarged reconstructions of Figure 4 in the text. A.) Copper (cyan), carbon (red), nitrogen (green) overlaid in the front view of the reconstruction. B.) A side view of the same reconstruction shown in A. C) Reconstruction with the same element scheme and orientation as $\mathrm{A}$, with the addition of an iso-concentration volume representing carbon concentrations of 5 at $\%$ or greater. D.) Same reconstruction as seen in C, but oriented to see the two separate spheres in this sample.

Reconstruction parameters: ICP: 1.65, K-factor: 3.30, Detector Efficiency: 0.5. For smoother and more defined iso-surfaces, the delocalization and voxel size were set to [4nm, $4 \mathrm{~nm}, 4 \mathrm{~nm}$ ] and $[1.5 \mathrm{~nm}, 1.5 \mathrm{~nm}, 1.5 \mathrm{~nm}]$ respectively.

Figure 4 Mass Spectrum

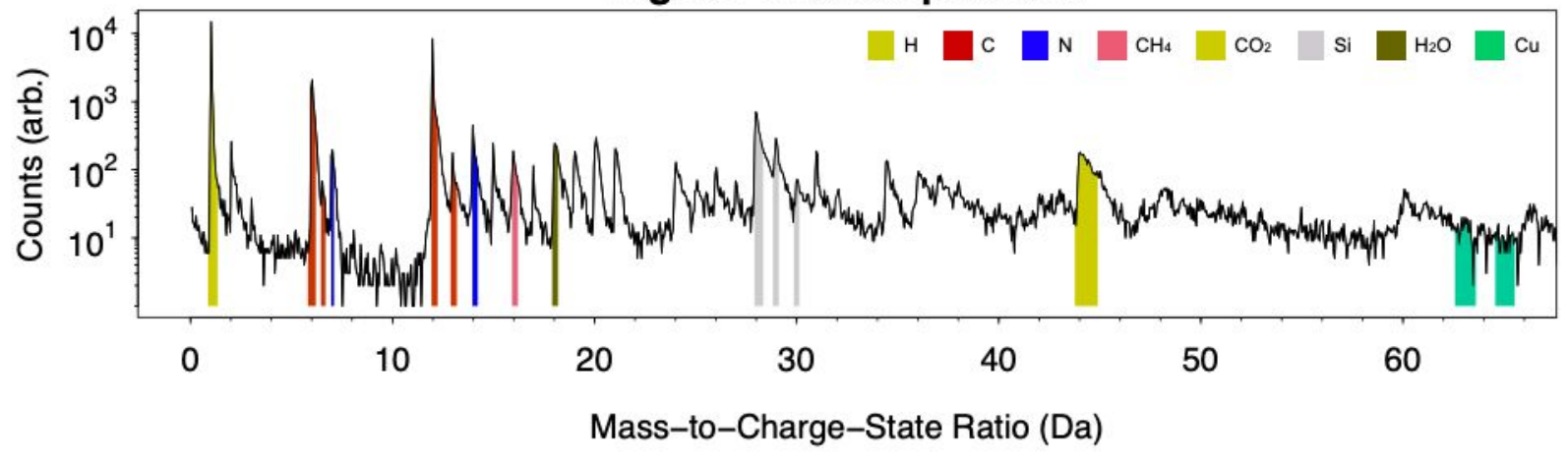

Figure S5: Mass spectrum of the volume enclosed in the $\mathrm{C}$ iso-concentration which is greater than 5 at $\%$ (depicted as a red volume in Figure SI 4 C\&D). 


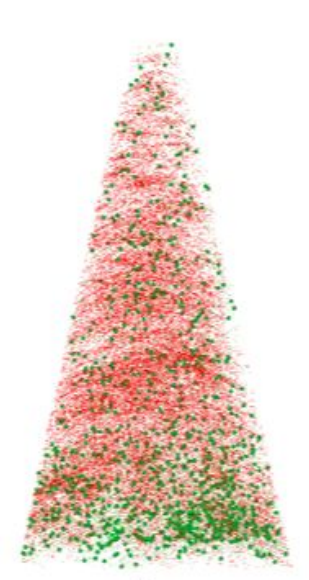

A

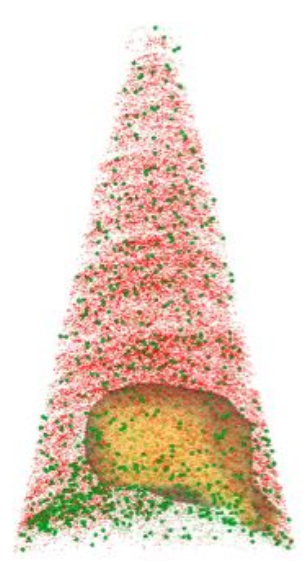

B

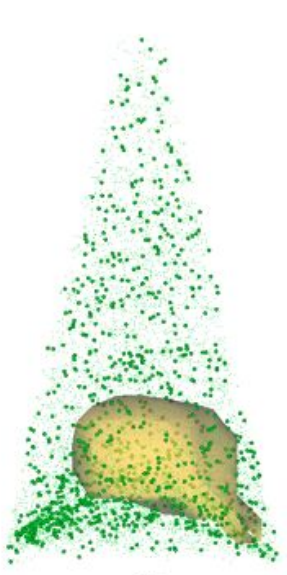

C

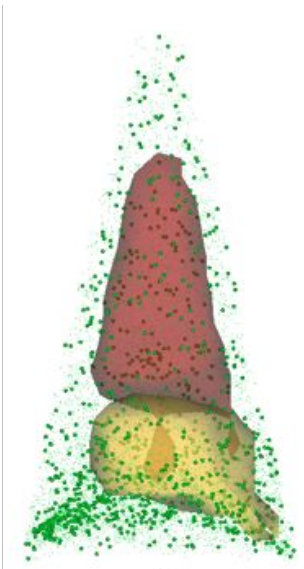

D

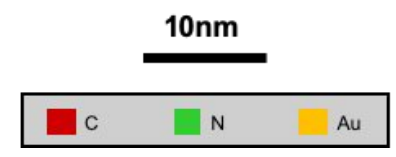

Figure S6: Enlarged reconstructions of the sample in Figure 6a. A.) Carbon (red points) and nitrogen (green spheres) B.) Carbon and nitrogen overlaid with an additional iso-concentration volume which includes concentrations greater than 0.4 at \% gold. C) Nitrogen (green spheres to enhance visibility) overlaid with the same gold iso-concentration as depicted in B. D.) Same reconstruction as seen in $\mathrm{C}$ but including an iso-concentration volume which illustrates where the sample is greater than 11.5 at $\%$ carbon.

Reconstruction parameters: ICP: 1.65, K-factor: 3.30, Detector Efficiency 0.55\%. For smoother and more defined iso-surfaces, the delocalization and voxel size set to [5nm, $5 \mathrm{~nm}, 5 \mathrm{~nm}]$ and [2nm, $2 \mathrm{~nm}, 2 \mathrm{~nm}]$ respectively.

Figure 6a Mass Spectrum

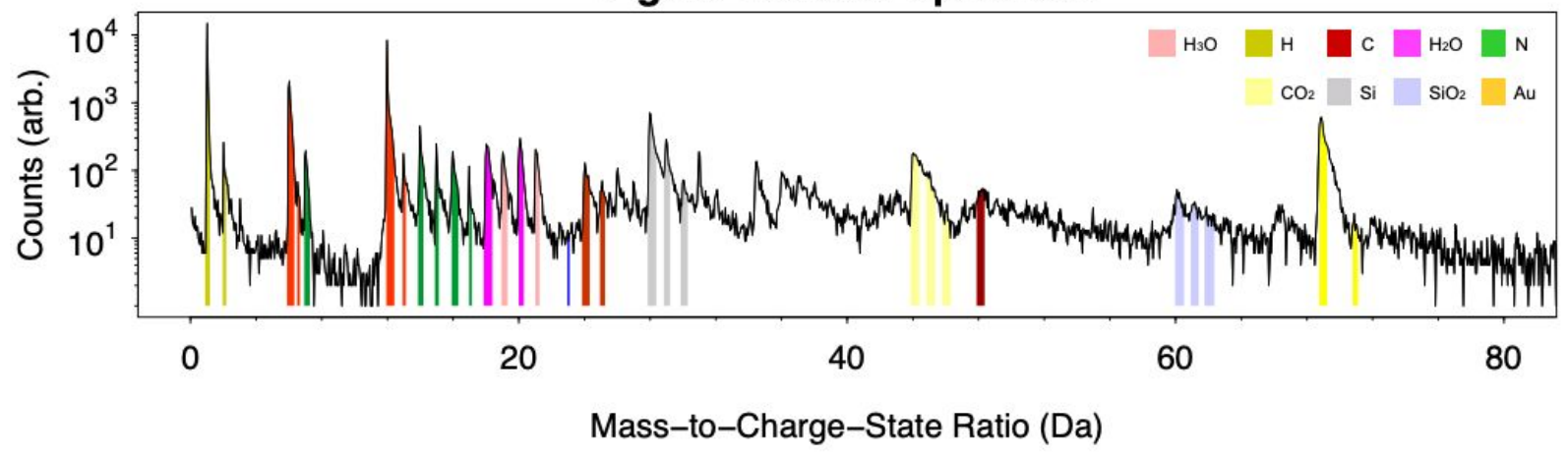

Figure S7: Raw mass spectra of the volume enclosed in the $\mathrm{C}$ iso-concentration which is greater than 11 at\% (depicted as a red volume in Figure $\mathrm{S} 6 \mathrm{D}$ ). Note that peak overlap for $\mathrm{N}^{2+}$ and $\mathrm{Si}^{1+}$ is apparent in the $28 \mathrm{Da}$ region. Here it is identified as $\mathrm{Si}^{1+}$ due to isotope peaks matching that of silicon rather than $\mathrm{N}^{1+}$. 


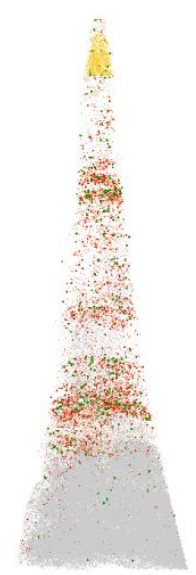

A

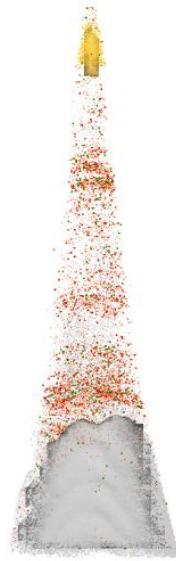

B

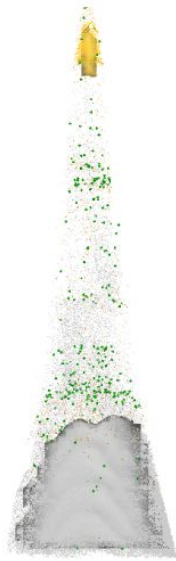

C

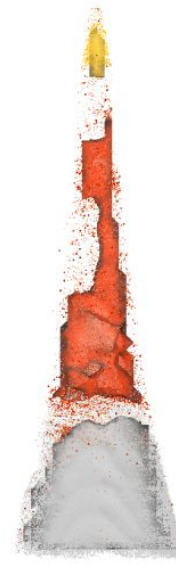

D

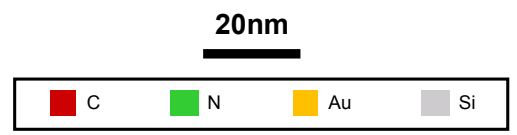

Figure S8: Enlarged reconstructions of the sample in Figure 6b. A.) Reconstruction with silicon (grey points), gold (gold points), carbon (red points) and nitrogen (green spheres) B.) The same reconstruction as in A with additional iso-concentration volumes which include concentrations greater than 5 at \% gold (gold color) and greater than 20 at $\%$ silicon (grey color). C) Nitrogen only (green spheres to enhance visibility) overlaid with the same gold and silicon isoconcentration as depicted in B. D.) Same reconstruction as seen in B but including an isoconcentration volume which illustrates where the sample is greater than 20 at $\%$ carbon.

Reconstruction parameters: ICP: 1.8, K-factor: 3.30, Detector Efficiency: 0.3\%. For smoother and more defined iso-surfaces, the delocalization and voxel size were set to [3nm, $3 \mathrm{~nm}, 3 \mathrm{~nm}$ ] and $[2 \mathrm{~nm}, 2 \mathrm{~nm}, 2 \mathrm{~nm}]$ respectively.

Figure 6b Mass Spectrum

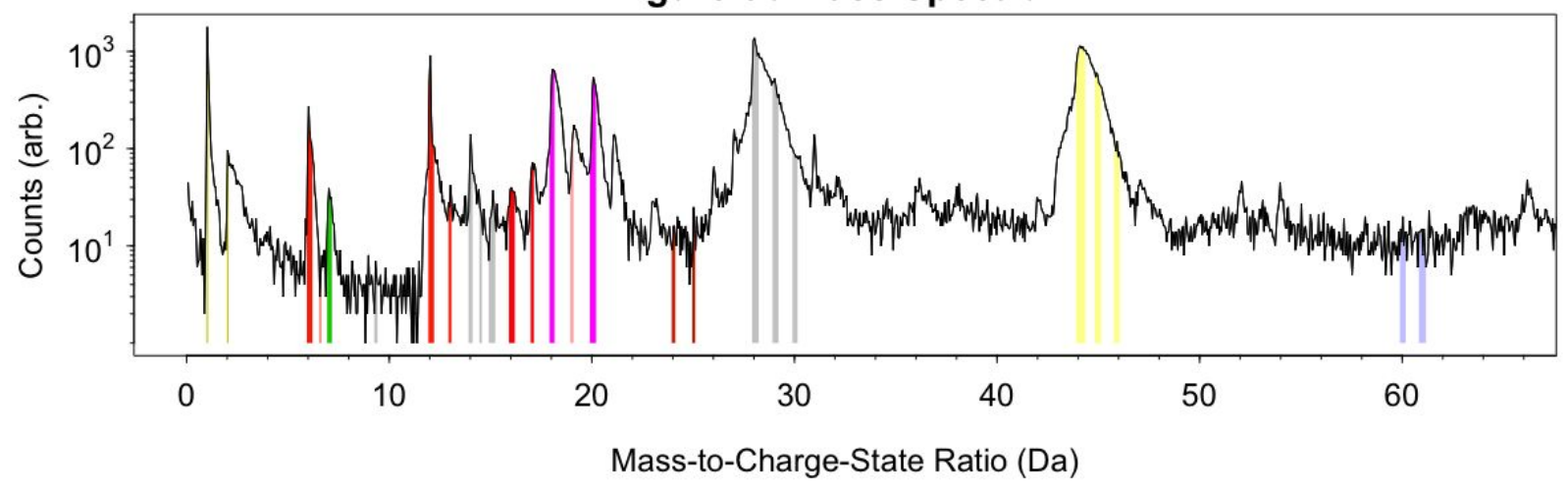

Figure S9: Raw mass spectra from the data collected within the $\mathrm{C}$ iso-concentration which is greater than 20 at\% (depicted as a red volume in Figure S8D). 


\section{References:}

(1) Rotkina, L.; Oh, S.; Eckstein, J. N.; Rotkin, S. V. Logarithmic Behavior of the Conductivity of Electron-Beam Deposited Granular Pt/C Nanowires. Phys. Rev. B 2005, 72 (23), 233407.

(2) Gerstl, S.; Morrone, A.; Kvitek, R. Three-Dimensional Nanoscale Characterization of Pt Deposition from an Organometallic Precursor Induced by a Focused Ion Beam. Microsc. Microanal. 2006, 12 (S02), 1252-1253.

(3) Diercks, D. R.; Gorman, B. P.; Mulders, J. J. L. Electron Beam-Induced Deposition for Atom Probe Tomography Specimen Capping Layers. Microsc. Microanal. 2017, 23 (2), $321-328$. 